\title{
Characterization of Rice Husk-Based Catalyst Prepared via Conventional and Microwave Carbonisation
}

\author{
Dalila Touhami ${ }^{1 \ddagger}$, Zongyuan Zhu ${ }^{1 \ddagger}$, Winnie Sinan Balan ${ }^{2}$, Jidon Janaun ${ }^{2}$, Stephanie \\ Haywood $^{1}$, Sharif H. Zein ${ }^{1 *}$ \\ ${ }^{1}$ School of Engineering, University of Hull, HU6 7RX, U.K., \\ ${ }^{2}$ Faculty of Engineering, Universiti Malaysia Sabah, Jalan UMS, 88400 Kota Kinabalu, \\ Sabah, Malaysia \\ Email: $\underline{\text { s.h.zein@ @ull.ac.uk }}$
}

\begin{abstract}
Carbon-based sulphonated catalysts (CBSCs) were made from rice husk for biodiesel production. The CBSCs were prepared by microwave (MW) and conventional heating processes from the same feedstock. In both heating systems, the preparation was a two-step process: carbonisation and sulphonation. The aim of this study was to use MW heating to reduce the conventional $\mathrm{CBSC}$ preparation time and enhance the $-\mathrm{SO}_{3} \mathrm{H}$ group attachment to the solid catalyst. The biomass based solid acid catalysts from the two systems were characterised and compared in terms of physicochemical properties including: sulphonation, morphology, surface area and structure. The reaction times for MW assisted carbonisation and for sulphonation were significantly reduced compared to the conventional heating system; these were $30 \mathrm{~min}$ vs $4 \mathrm{~h}$ and $20 \mathrm{~min}$ vs $12 \mathrm{~h}$, respectively. The MW prepared catalyst showed higher sulphur content $(4.91 \%)$ as compared to the conventional catalyst $(2.10 \%)$. The FTIR analysis showed well distinguished peaks for $-\mathrm{SO}_{3} \mathrm{H}$ for the $\mathrm{MW}$ prepared catalyst suggesting the solid catalyst was successfully sulphonated, while these peaks were very weak for the conventional catalyst. SEM analysis revealed a highly porous structure in the MW prepared catalyst, whilst a denser solid resulted for its conventionally prepared analogue, owing to the higher temperatures applied and longer sulphonation time. The surface area for the MW was higher than the conventionally prepared catalysts $\left(43.63 \mathrm{~m}^{2} / \mathrm{g}\right.$ and $37.01 \mathrm{~m}^{2} / \mathrm{g}$, respectively). The structure of the samples was identified as amorphous for both catalysts as confirmed by $\mathrm{XRD}$. The prepared CBSC is expected to catalyse biodiesel production reaction as evidenced by its total acidity and surface area.
\end{abstract}


Keywords: biomass, carbonisation, solid acid catalyst, rice husk, microwave energy.

† First Authors: equally contributed

\begin{abstract}
Abbreviations:
MW: microwave, CBSC: carbon-based sulphonated catalyst, RH: rice husk, CRH: carbonised rice husk, FFA: free fatty acid.
\end{abstract}

\title{
1. Introduction
}

In recent years, the industrial use of agricultural waste has gained attention, due to advantages such as low cost, lack of competition with food supply, reduced dependence on non-renewable energy/material source and its potential to reduce greenhouse gas emission [1-4]. Various agricultural wastes have been explored, including rice husk $(\mathrm{RH})$, sugarcane bagasse, coconut husk, rice straw, wheat straw, and so forth [2-7]. $\mathrm{RH}$ is a major agricultural by-product in several parts of Asia; mainly in China and India, which have $33 \%$ and $22 \%$ of the global rice harvest, respectively [1]. RH is a promising feedstock for industrial application, due to its wide abundance and composition[1, 6, 8, 9]. Similar to other lignocellulosic materials, $\mathrm{RH}$ is composed of cellulose, hemicellulose, lignin and ash. More importantly, this biomass waste possesses unique properties, such as high silica content, high porosity, light weight and high external surface area $[1,10]$. These properties makes it an ideal biomass waste for use as a potential metal adsorbent, a ligand in construction material, a silica source in ceramics, a catalyst or a catalyst support for other applications $[11,12]$. Transesterification reactions for long chain esters (biodiesel) production are usually catalysed by homogenous or heterogeneous catalysts. Most common homogeneous catalysts are liquid acids. Acid assisted transesterification has been widely used for long chain ester production [14-15]. Acids such as sulfuric acid, hydrochloric acid and sulphonic acid are common catalysts with an effective catalytic performance $[14,15]$. However, there are some drawbacks of these liquid acid 
catalysts, such as environment pollution, equipment corrosion, product separation issues and successive reaction operation is also not practical [16]. Solid acid materials, eco-friendly and reusable heterogeneous catalysts have gained increasing attention and are favoured over homogenous acid catalysts. Since, solid acid catalysts can be easily separated from reaction systems, so they can be recovered and reused.

An ideal solid acid catalyst for biodiesel production should have a high density of strong acidic sites, excellent stability, high porosity, low cost and hydrophobic surfaces so the catalyst is not deactivated [17]. Among the most promising solid catalysts are the carbon- based sulphonated catalysts (CBSCs). CBSCs possess a carbon supporting framework and can provide a high density of strong acid sites $\left(-\mathrm{SO}_{3} \mathrm{H}\right.$ group); they also resist water deactivation during the transesterification reaction. Furthermore, CBSCs have other acid groups such as the carboxylic group $(-\mathrm{COOH})$ and hydroxyl group $(-\mathrm{OH})$, thus differing from conventional solid acids bearing a single functional group $[18,19]$. Owing to the extensive sources of raw material, cheap price and simple preparation, biomass material is widely used for catalyst preparation [16, 20-26]. Different catalyst preparation methods have been developed, such as hydrothermal conversion and pyrolysis, followed by sulphonation $[16,21,26]$. Several highly efficient solid acid catalysts prepared by these methods have been reported [16, 20, 26]. However, the conventional biomass derived solid acid catalyst preparations were generally performed under high temperature $\left(400-800{ }^{\circ} \mathrm{C}\right)$ and long reaction time (4-15 hours), suggesting the conventional catalyst preparation processes are time consuming and energy intensive. Microwave (MW) energy has become a widely accepted alternative energy source. Since this form of energy is faster, more uniform than conventional heating and is widely applied to assist biomass pyrolysis, hydrolysis and pre-treatment [27-30]. RH has been used as a biomass waste for several applications as mentioned above. However, MW assisted RH based catalyst preparation was only reported under alkaline conditions [31]. As far as we are aware, MW facilitated RH based solid acid catalyst under acid conditions has not been reported before. In 
the present study, RH derived CBSC (RH CBSC) were prepared using two heating systems for comparison purposes: a) conventional heating to induce pyrolysis, followed by sulphonation and b) MW assisted carbonisation and sulphonation. The aim of the current study is two fold: 1) to prepare RH based CBSCs using the two heating systems; 2) to characterise and compare the MW assisted RH CBSC and the conventional heating facilitated RH CBSC made from the same feedstock.

\section{Experimental}

\subsection{Conventional CBSC catalyst preparation}

Conventional CBCS was prepared by a two-step process: carbonisation and sulphonation. Rice husk was supplied from a rice mill, Kilang Seri Padi Dusun Sdn. Bhd., located in Kota Belud, Sabah, Malaysia. The RH was pyrolysed in a tube furnace (Eurotherm 2116) under nitrogen flow of $100 \mathrm{ml} \mathrm{min}{ }^{-1}$ at $400{ }^{\circ} \mathrm{C}$ for $4 \mathrm{~h}$. The resultant char was ground using a pestle and mortar into fine powder. $20 \mathrm{~g}$ of the RH biochar was sulphonated in a 3-necked round bottom flask, using $74.0 \mathrm{~mL}$ of fuming sulfuric acid $\left(\mathrm{H}_{2} \mathrm{SO}_{4}\right)\left(20 \mathrm{wt} . \%\right.$ free $\left.\mathrm{SO}_{3}\right)$ at $160{ }^{\circ} \mathrm{C}$ for $12 \mathrm{~h}$ under nitrogen flow [32]. After cooling to room temperature, the sulphonated rice husk was heated to $80{ }^{\circ} \mathrm{C}$ in $1000 \mathrm{~mL}$ distilled water, and stirred using a magnetic bar for $1 \mathrm{~h}$. The char was filtered for further washing. The washing was repeated until no sulphate ion was detected in the washed water, and the $\mathrm{pH}$ was close to neutral. Then, the sample was dried overnight in an oven at $104{ }^{\circ} \mathrm{C}[32]$.

\subsection{Microwave CBSC catalyst preparation}

RH was supplied from a rice mill, Kilang Seri Padi Dusun Sdn. Bhd., located in Kota Belud, Sabah, Malaysia, following the milling process. The sample particles were 8 to $10 \mathrm{~mm}$ long, 2.0 to $2.5 \mathrm{~mm}$ wide and 0.1 to $0.15 \mathrm{~mm}$ thick. The $\mathrm{RH}$ was blended before use. Rice husk samples each of $3 \mathrm{~g}$ were mixed with $3 \mathrm{ml}$ or $4 \mathrm{ml}$ of $1 \mathrm{M}$ or $2 \mathrm{M} \mathrm{H}_{2} \mathrm{SO}_{4}$, followed by microwave incomplete carbonisation under the conditions of $200{ }^{\circ} \mathrm{C}$ for $30 \mathrm{~min}$ in a PTFE reactor (ETHOS 
EX, Microwave Extraction System, Milesone, US). The temperature in the MW was monitored using an IR temperature probe. The carbonised biomass material was then dried overnight in an oven $\left(50^{\circ} \mathrm{C}\right)$, followed by hand milling into fine powder. Black fine powder $(2 \mathrm{~g})$ was mixed with $20 \% \mathrm{SO}_{3}$ fuming sulfuric acid $(8 \mathrm{ml})$ in the microwave reactor. The sulphonation was performed in the microwave between $5 \mathrm{~min}$ and $20 \mathrm{~min}$. The carbonisation and sulphonation conditions can be found in Table S1. After cooling to room temperature, the mixture was washed with deionized water to neutrality. The resulting black solid was dried overnight at 100 ${ }^{\circ} \mathrm{C}$.

\subsection{Characterisation of RH-CBSCs}

\subsubsection{FTIR spectroscopy}

The chemical composition of the CBSC solid residues before and after the pre-treatments were analysed by attenuated total reflection-Fourier transformed infrared spectroscopy (ATR-FTIR). ATR-FTIR was conducted using a Thermo scientific PIKE Nicolet IS5 with built-in diamondgermanium ATR single reflection crystal. Samples were pressed firmly against the diamond surface using a screw-loaded anvil. Sample spectra were obtained using 32 scans in the wave number range of 650 to $4000 \mathrm{~cm}^{-1}$ at a spectral resolution of $4 \mathrm{~cm}^{-1}$.

\subsubsection{Total acidity}

Total acidity of the CBSC was measured by acid-base back titration. $60 \mathrm{ml}$ of $\mathrm{NaOH}(8 \mathrm{mM})$ was added to $0.1 \mathrm{~g}$ of the catalyst in a conical flask and stirred for 30 minutes at room temperature. Then the mixture was titrated with $\mathrm{HCl}(20 \mathrm{mM})$ and the changes in the acidity was measured by $\mathrm{pH}$ meter (Mettler Toledo, UK). When the $\mathrm{pH}$ reached 7.00 it indicated the end point of the titration.

\subsubsection{Scanning electron microscopy (SEM)}

Morphological characteristics of CBSC were studied using a scanning electron microscope fitted with a tungsten filament cathode (Stereoscan 360, Cambridge Instruments). The samples 
were sputter-coated with $7 \mathrm{~nm}$ Au to enhance the conductivity for better SEM images. Images were obtained under vacuum at $10-15 \mathrm{kV}$ acceleration voltage.

\subsubsection{X-ray diffraction (XRD)}

XRD analysis of the catalysts was made on a Philips Diffractometer (model PW 3710) with X'Pert PRO graphics software package. An aluminium-glass composite sample holder with a circular slot of $1 \mathrm{~cm}$ diameter was filled with the powdered sample using the front loading method. The samples were analysed using monochromated cobalt radiation $(\lambda=1.540 \AA)$ with a nickel filter. The Bragg angle was in the $2 \theta$ angle range of $10-80^{\circ}$ and a scan speed of $0.72^{\circ}$ per minute with a step-size of $0.015^{\circ}$ was used. The Philips diffractometer was operated at 40 $\mathrm{kV}$ and $40 \mathrm{~mA}$.

\subsubsection{Elemental analysis and Inductively Coupled Plasma-Mass Spectrometry (ICP)}

CHNS content of the RH and the CBSC were determined using a Carlo Erba EA 1108 Fisons instrument. The ICP analysis were performed following aqua regia acid digestion. The aqua regia acid digestion was carried out using $3 \mathrm{ml}$ nitric acid $\left(\mathrm{HNO}_{3}\right), 1 \mathrm{ml}$ hydrofluoric acid (HF) and $1 \mathrm{ml}$ hydrochloric acid $(\mathrm{HCl})$ at $170^{\circ} \mathrm{C}$. The digestion was followed by ICP analysis.

\subsubsection{Brunauer- Emmett-Teller (BET) analysis}

The specific surface area and pore volume were determined by nitrogen adsorption and desorption isotherms measured at $77 \mathrm{~K}$ using a Micromeritics Surface Area and Porosity Analyzer. The isotherms were analysed to obtain the specific surface area according to the BET model. The pore volume within the solid acid catalysts were evaluated from the isotherms using the BJH (Barrett-Joyner-Halenda) model.

\section{Results and Discussion}

Since the first reported highly efficient carbon-based solid acid catalyst preparation [22], the incomplete carbonisation reaction using $\mathrm{H}_{2} \mathrm{SO}_{4}$ has been widely adopted to produce aromatic 
carbon sheets as a catalyst support $[16,17,33,34]$. The incomplete carbonisation is followed by a sulphonation reaction, that is, $\mathrm{SO}_{3} \mathrm{H}$ group attachment to the carbon sheets. Herein, the incomplete carbonisation was performed at $200{ }^{\circ} \mathrm{C}$ using different ratios of $\mathrm{RH}$ to $\mathrm{H}_{2} \mathrm{SO}_{4}$ (Supplement information, Table S1). The carbon-based solid was sulphonated using a fixed ratio of RH to fuming sulfuric acid (20\%) and different reaction times (Supplement information, Table $\mathrm{S} 1$ ). The ratio of the $\mathrm{RH}$ to $\mathrm{H}_{2} \mathrm{SO}_{4}$ for the carbonisation step was investigated along with the sulphonation time. Furthermore, the MW prepared CBSC and the conventionally prepared CBSC are compared in terms of their properties.

\subsection{Elemental analysis and total acidity of RH and RH CBSCs}

The CHNS content of RH and CBSC prepared by MW and conventional heating systems are presented in Table 1. The RH feedstock was mainly composed of 36.6 wt.\% C, 4.7 wt.\% H, 0.4 wt. $\%$ N, 54.1 wt. $\% \mathrm{O}$ and 4.15 wt. \% ash ( with 3.94 wt. \% Si). The amounts of $\mathrm{C}$ and N in the prepared CBSCs did not vary significantly compared to those in the RH feedstock. However, the $\mathrm{H}$ content was remarkably reduced (ca. $50 \%$ ) following the carbonisation and sulphonation reactions as compared to the feedstock. The reduced amount of $\mathrm{H}$, suggests its covalent binding with sulphur $-\mathrm{SO}_{3} \mathrm{H}$ presumably exchanged in $\mathrm{CH}$ bonds [36]. Moreover, the O content was reduced by $20 \%$ most likely due to the dehydration and condensation reactions $[35,36]$. Sulphur was detected with 0.03 wt. \% in the raw material. The conventional and MW catalyst sulphonation processes resulted in S content of 1.11 wt. $\%$ and $2.52-4.91$ wt. \% respectively (Table 2). These results were confirmed by ICP heavy metal analysis (see Supplement Information, Table S1). The sulphur content in the MW sulphonated catalysts increased by two orders of magnitude as compared to the sulphur originally found in the raw RH (Table 2), while the conventionally prepared catalyst resulted in only 30-fold increase of sulphur content relative to the feedstock. The ratio of RH to acid showed no effect in terms of the sulphur content in the range investigated. Similarly, the MW sulphonation for 20 min seemed slightly better than for shorter times. The sulphur content is slightly higher as can be 
seen for samples CBSC-1-3-5 and CBSC-1-3-20 sulphonated at 5 min and 20 min respectively (Table 1). The sulphonation time effect can be seen in Supplement Information, Table S1.

Table 1. C, H, N, S content in RH feedstock and MW \& Conv. CBSC

\begin{tabular}{lllllll}
\hline Entry & \multicolumn{7}{c}{ Elemental component (wt. \%) } & \\
\cline { 2 - 7 } & $\mathrm{C}$ & $\mathrm{H}$ & $\mathrm{N}$ & $\mathrm{S}$ & $\mathrm{O}^{\mathrm{a}}$ & Ash \\
\hline RH & 36.56 & 4.66 & 0.40 & 0.03 & 54.23 & 4.15 \\
CBSC-1-3-5 & 39.21 & 2.68 & 0.40 & 4.22 & 43.33 & 10.16 \\
CBSC-1-3-20 & 38.71 & 2.27 & 0.46 & 4.91 & 44.22 & 9.43 \\
CBSC-2-4-20 & 33.63 & 2.30 & 0.28 & 3.85 & 49.80 & 10.14 \\
Conv. CBSC & 31.29 & 1.53 & 0.40 & 1.11 & 49.75 & 15.92
\end{tabular}

* Conv. CBSC: Conventional carbon based solid catalyst. CBSC-1-3-5: the first number designates the acid concentration, the second number is the acid volume and the third number is the sulphonation time. The elemental composition was calculated on a dry-weight basis (oxygen was determined by difference)

In order to investigate the relationship of the sulphur content with the total acidity of the prepared catalysts, the samples with higher sulphur content (CBSC-1-3-5, CBSC-1-3-20 and CBSC-2-4-20) and the samples with lower sulphur content (CBSC-1-4-5 and CBSC-1-4-10) were chosen for the total acid density test (Table 2). Total acidity comprises the sulphonic acid group $\left(\mathrm{SO}_{3} \mathrm{H}\right)$, carboxylic group $(\mathrm{COOH})$ and hydroxyl group $(\mathrm{OH})$. High acid sites in solid catalysts are known to promote high catalytic acidity [37]. Strong acidity is usually attributed to the sulphonic acid group $\left(\mathrm{SO}_{3} \mathrm{H}\right)$, high loading of the sulphonic acid group was shown to increase the catalytic activity [37]. The total acidity increases almost proportionally with the sulphur content, indicating that part of the acidity is due to $\mathrm{SO}_{3} \mathrm{H}$ group attachment. The total acidity of the MW prepared catalysts achieved in this work is around twice that of their conventionally prepared analogues (Table 2). Liu et al. prepared carbon-based solid catalyst 
by sulfonating activated carbon $\left(\mathrm{AC}-\mathrm{SO}_{3} \mathrm{H}\right)$ which resulted in only $1.01 \mathrm{mmol} \mathrm{H}^{+} / \mathrm{g}$ total acid density (Table 2) [38]. The same group also prepared corn straw based sulphonated catalysts using conventional heating (carbonisation: $\geq 250{ }^{\circ} \mathrm{C}, 1 \mathrm{~h}$; sulphonation: $80{ }^{\circ} \mathrm{C}, 4 \mathrm{~h}$ ). Their results showed $2.64 \mathrm{mmol} \mathrm{H} / \mathrm{g}$ total acid density [20]. Another reported study on different feedstock carbon-based sulphonated catalysts showed higher S content and relatively lower total acidity [39] (see Table 2). The MW prepared catalysts in this work showed the highest sulphur content and total acidity compared to the above-mentioned conventionally prepared biomass based catalysts. Furthermore, the MW catalysts showed comparable total acid density to the commercial Amberlyst-15 (avr. MW CBSC $3.85 \mathrm{mmol} \mathrm{H}^{+} / \mathrm{g}$ vs $4.20 \mathrm{mmol} \mathrm{H}^{+} / \mathrm{g}$ ) [20].

Table 2 Total acid density of MW CBSC and Conv. CBSC

\begin{tabular}{|c|c|c|}
\hline Sample & $\begin{array}{l}\text { S content } \\
(\%)\end{array}$ & $\begin{array}{l}\text { Total acidity } \\
\mathrm{mmol} \mathrm{H}^{+} / \mathrm{g}\end{array}$ \\
\hline CBSC-1-3-5 & 4.22 & 3.90 \\
\hline CBSC-1-3-20 & 4.91 & 4.24 \\
\hline CBSC-2-4-20 a & 3.85 & 4.36 \\
\hline CBSC $-1-4-5^{\mathrm{a}}$ & 2.52 & 3.54 \\
\hline CBSC-1-4-10 ${ }^{a}$ & 2.54 & 3.20 \\
\hline $\mathrm{AC}-\mathrm{SO}_{3} \mathrm{H}^{[38]}$ & 0.90 & 1.01 \\
\hline Corn straw ${ }^{[20]}$ & & 2.64 \\
\hline D glucose derived catalyst ${ }^{[39]}$ & 4.70 & 1.60 \\
\hline Cellulose derived catalyst ${ }^{[39]}$ & 5.40 & 1.82 \\
\hline Starch derived catalyst ${ }^{[39]}$ & 5.90 & 1.97 \\
\hline Amberlyst 15 & - & 4.20 \\
\hline Conv. CBSC ${ }^{a}$ & 1.11 & 2.10 \\
\hline
\end{tabular}




\subsection{FT-IR absorption spectra and analysis}

The RH feedstock chemical changes upon carbonisation and sulphonation were qualitatively analysed by ATR-FTIR spectroscopy. RH is mainly composed of cellulose, hemicellulose, lignin and waxes. The lignocellulosic stucture consists of alkenes, esters, aromatics, ketones and alcohols. Figure 1a shows the rice husk feedstock spectrum. A sharp peak at $792 \mathrm{~cm}^{-1}$ related to O-Si-O stretching vibrations of silica group is observed [4]. The silica related peak remained following both the microwave and the conventional carbonisation and sulphonation processes as expected (Figure 1). It is important to note that the silica was not removed from the carbon based materials in both processes. Since, silica proved to maintain the mesoporous structure which otherwise will cause the carbon composites to collapse [40, 41]. The RH spectrum shows a broad band of a peak at $1030 \mathrm{~cm}^{-1}$ and a shoulder at $1054 \mathrm{~cm}^{-1}$ (Figure 1a). These peaks are attributed to $\mathrm{C}-\mathrm{O}$ stretching in the $\mathrm{C}-\mathrm{OH}$ and $\mathrm{C}-\mathrm{O}-\mathrm{C}$ stretching between the sugar units in celluose [42]. The peak at $1030 \mathrm{~cm}^{-1}$ related to cellulose disappeared upon carbonisatation of the RH (Figure $1 \mathrm{~b}$ and $\mathrm{c}$ ), this indicated its degradation by the two heating systems. Following the carbonisation and sulphonation, new peaks around $1040 \mathrm{~cm}^{-1}$ and 1080 $\mathrm{cm}^{-1}$ appear clearly in the MW prepared catalyst (Figure $1 \mathrm{~b}$ ), but are less distinguished in the conventional catalyst (Figure 1c). These newly appearing absorption bands at $1040 \mathrm{~cm}^{-1}$ and $1080 \mathrm{~cm}^{-1}$ represent the asymmetric and asymmetric stretching respectively of $\mathrm{S}=\mathrm{O}$ bonds of sulphonic acid $\left(\mathrm{SO}_{3}-\mathrm{H}\right)$ [43]. The sulphonation process was achieved in this case by a covalent attachment of $-\mathrm{SO}_{3} \mathrm{H}$ to the carbon framework through substitution of hydrogen in the $\mathrm{C}-\mathrm{H}$ bond [16]. The attachment of sulphur groups is further confirmed by the elemental analysis (Table 1 ) and the acidity test (Table 2). The $\mathrm{C}-\mathrm{H}$ vibration in cellulose and $\mathrm{C} 1-\mathrm{O}$ vibration in the syringyl ring derivatives at $1330 \mathrm{~cm}^{-1}$ and the $\mathrm{CH}_{2}$ cellulose plane bending vibrations at $1430 \mathrm{~cm}^{-1}$ are clearly visible in the RH FTIR spectrum (Figure 1a) [44]. Besides the peak at $1371 \mathrm{~cm}^{-1}$ that corresponds to the $\mathrm{C}-\mathrm{H}$ deformation in cellulose and hemicellulose. The $\mathrm{C}-\mathrm{H}$ 
related peaks $\left(1330 \mathrm{~cm}^{-1}\right.$ and $\left.1370 \mathrm{~cm}^{-1}\right)$ wither after the carbonisation process indicating the degradation of cellulose/hemicellulose [45], while the $\mathrm{C}-\mathrm{H}$ deformation in cellulose and hemicellulose at $1430 \mathrm{~cm}^{-1}$ band appears visibly broader and weaker in both the MW and conventionally heated solid acid catalysts. This is not surprising since the heating applied was higher than $200{ }^{\circ} \mathrm{C}$ in both systems and the decomposition of the cellulose in this case is significant. Furthermore, the lignin absorption band in the RH spectrum, at $1460 \mathrm{~cm}^{-1}$ ascribed to lignin methoxy groups $\left(-\mathrm{OCH}_{3}\right)$, the bands at $1510 \mathrm{~cm}^{-1}$ and $1600 \mathrm{~cm}^{-1}$ related to the phenolic ring vibrations of lignin and the peak at $1731 \mathrm{~cm}^{-1}$ representing the ester bond $(\mathrm{C}=\mathrm{O})$ between hemicelluloses and lignin also disappear after the two different carbonisation processes [29, 45]. This reflects the destruction of the lignin aromatic system and formation of a new broad band at $1614 \mathrm{~cm}^{-1}$ after both MW and conventional heating processes (Figure $1 \mathrm{~b}$ and c). The $1614 \mathrm{~cm}^{-1}$ band is attributed to a $\mathrm{C}=\mathrm{C}$ stretching of alkenes and some newly formed aromatics [47]. The disappearance of the peak at $1731 \mathrm{~cm}^{-1}$ in the $\mathrm{RH}$ and the appearance of the peak at $1710 \mathrm{~cm}^{-1}$ that is related to $\mathrm{C}=\mathrm{O}$ suggests that the sulphonation process also produces a certain amount of weak acid, such as carboxylic acid. Hence, the low temperature MW assisted carbonisation and sulphonation process of $\mathrm{RH}$ feedstock produced both strong and weak acid groups on the surface of the catalyst. 


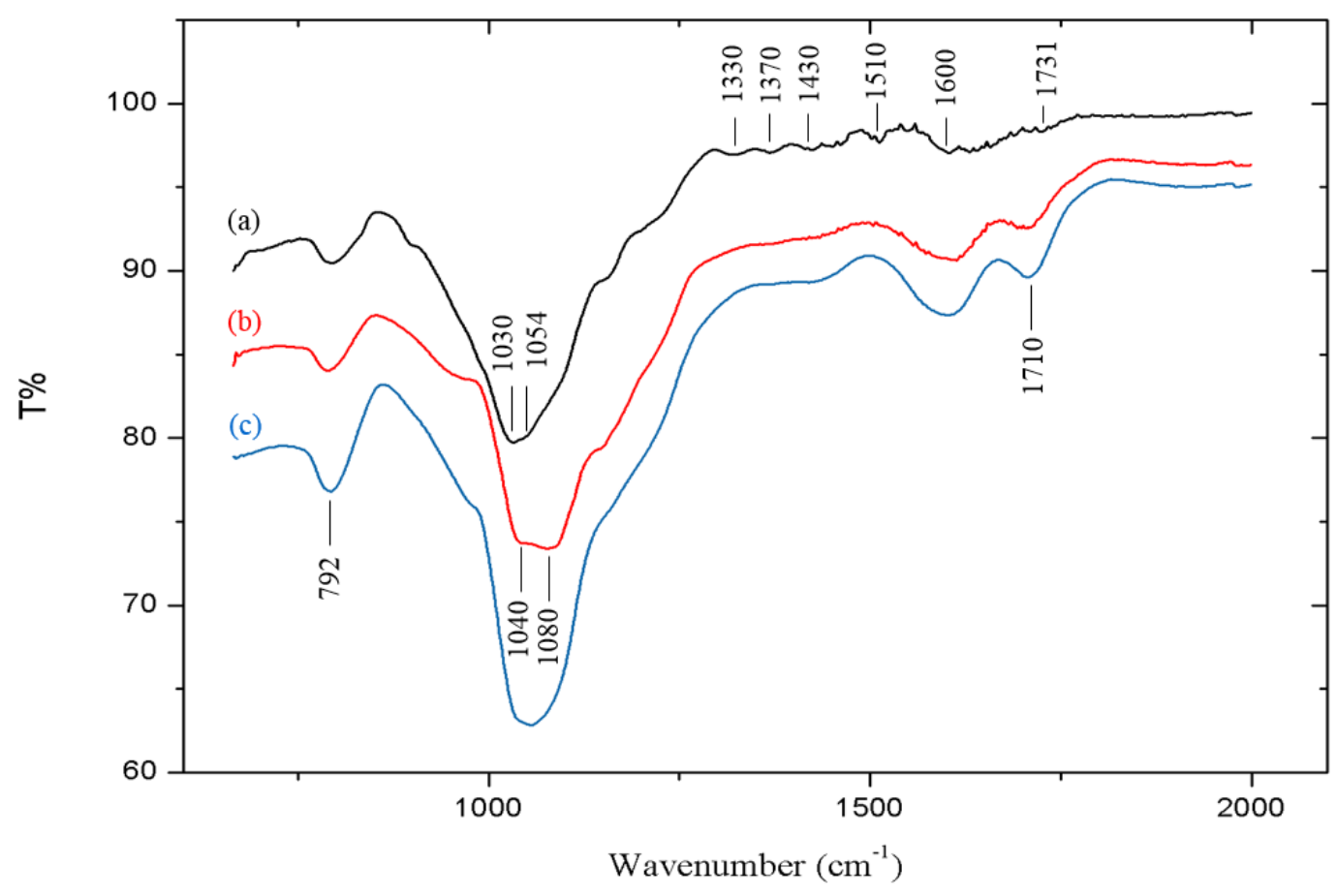

Figure 1 FTIR spectra of (a) RH feedstock, (b) MW CBSC and (c) Conv. CBSC

\subsection{SEM Morphological analysis}

The morphology of the RH feedstock shows macrostructural aggregates with a size range 6-10 mm (Figure S1 d and e, Supplement Information). The RH particles (Figure 2a) consist of an external surface with a corrugated structure similar in nature to references $[31,32]$. The external walls are supported by an inherent longitudinal mesoporous layer with ca. $20 \mu \mathrm{m}$ pore height supported by a transversal porous layer (ca. $10 \mu \mathrm{m}$ length). This feature is seen as $90^{\circ}$ crossed longitudinal/transversal channels (cross section view, Figure 2a). The channels are covered by a featureless layer. Figure 2a bottom shows the featureless biomass surface with some bundles.

The MW carbonisation process decomposes the organic components of the rice husk leading to induced cracks (Figure S1 d). In Figure 2c, the RH self-construction was preserved in the carbonised samples. While, this process induced cracks in the external walls of the particles (Figure S1 d) and probably removed the underneath covering layer (Figure 2b), it also formed porous structure in the internal walls with average pore size ca. $2 \mu \mathrm{m}$. The vascular bundles of 
RH were still maintained after sulphonation. Furthermore, a large amount of micropores and mesopores with pore diameters of $1-10 \mu \mathrm{m}$ and $5-20 \mathrm{~nm}$ can be clearly observed in Figure $2 \mathrm{~b}$ and Figure S1b, Supplement Information, respectively. The acid addition was demonstrated to induce the porosity of carbon materials with high surface area and large pore volume [31]. Figure 2c shows the morphology of CBSC prepared by the conventional heating method. The CBSC surface seems denser than the MW CBSC. It also appears damaged and covered with seemingly solid biomass fragments. By comparison with the conventional heating preparation method, the MW prepared CBSC led to a highly porous structure. The acid induced mesoporosity is further confirmed by the BET surface area measurements described in the following section.

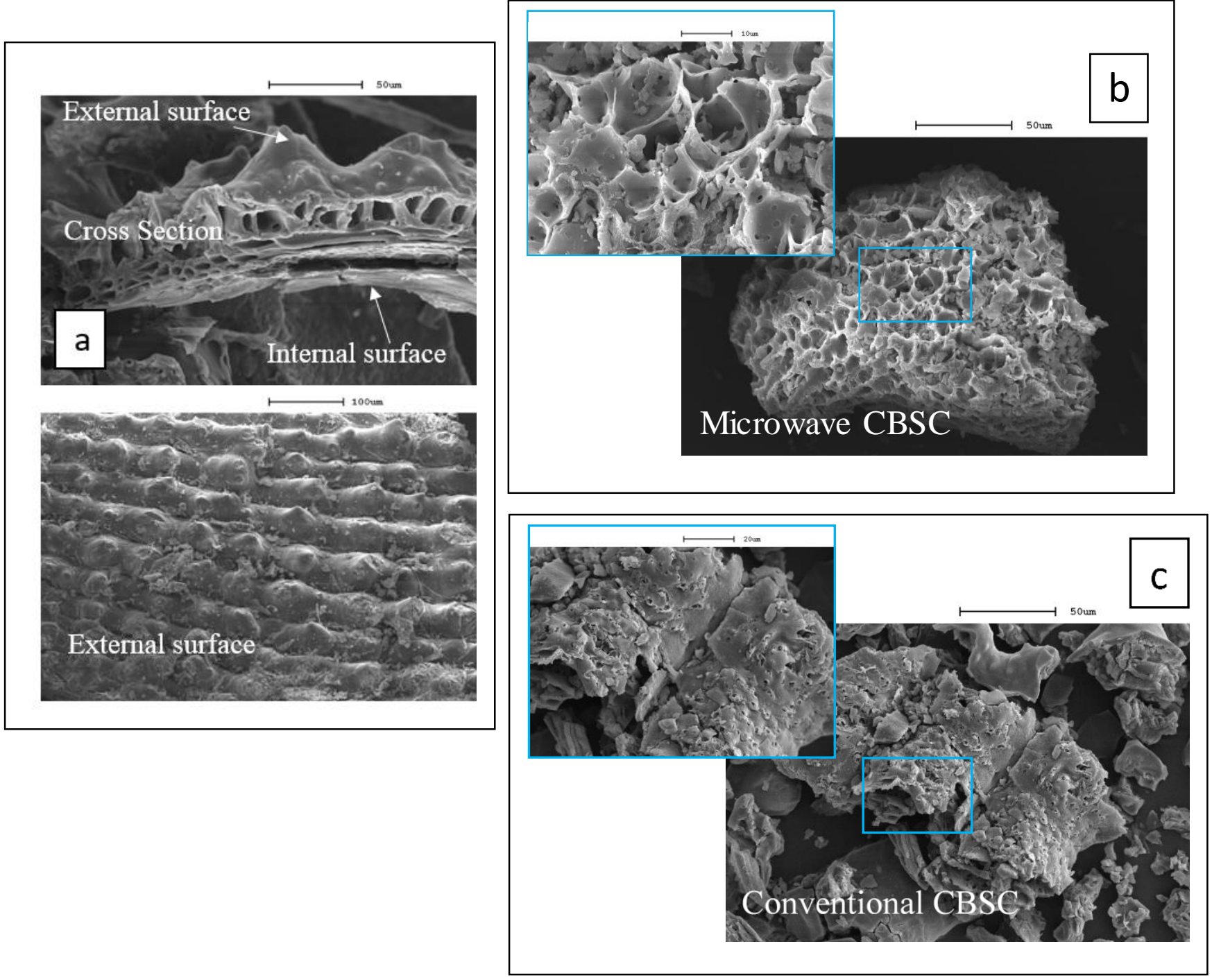


Figure 2 SEM of RH feedstock and CBSC samples (a) RH feedstock. Top: cross section. Bottom: external surface, (b) MW CBSC and (c) Conv. CBSC

\subsection{Surface characterization}

In order to gain further insight into structural changes the carbonised $\mathrm{RH}(\mathrm{CRH})$ and the CBSC porosity was analysed using the BET method. The surface area, pore volume and pore diameter for RH, carbonised samples and CBSC are shown in Table 3. The surface area and pore volume data reported herein was taken from Barrett-Joyner-Halenda $(\mathrm{BJH})$ desorption cumulative surface area and volume measured between $17 \AA$ and $3000 \AA$. The CBSC show microporosity with a pore size ranging from ca. $5 \mathrm{~nm}$ to ca. $10 \mathrm{~nm}$ (Table 3). The RH shows surface area of $10.43 \mathrm{~m}^{2} / \mathrm{g}$, this has increased at least 4-fold after carbonisation (not shown); following the sulphonation a further increase of $10-21 \%$ is observed. The catalysts sulphonated for $20 \mathrm{~min}$ showed the largest surface area of $43-48 \mathrm{~m}^{2} / \mathrm{g}$. The data at hand indicate that the microwave treatment has promoted the porosity; this is further observed from $60-80 \%$ increase of the pore volume for microwave prepared catalysts as compared to the raw RH. No correlation was observed between the microwave sulphonation time and the surface area of the CBSCs. However, the pore volume seems to increase with longer sulphonation time. This is illustrated by the $60 \%$ increase of pore volume upon 25 min additional sulphonation time in agreement with reference [48]. The conventionally prepared catalyst exhibited $15 \%$ lower surface area than the microwave prepared analogues (Table 3). Surprisingly, the pore volume of the Conv. CBSC reduced to $28 \%$ lower than the raw rice husk. This suggests the collapse of the carbon based structure resulting in elongated and nearly closed pores as shown in SEM images 
(Supplement Information, Figure S1). Lou et al. used different feedstock to make CBSC under conventional heating methods (Table 3). In contrast with their results, the catalyst in the current study presents a larger surface area and similar pore diameter. However, the pore volume of our catalysts is lower. Further investigation and study are needed to improve the pore volume in this study.

Table 3. BET characteristics of RH, CRH and CBSC samples

\begin{tabular}{|c|c|c|c|}
\hline Sample & $\begin{array}{l}\text { Surface Area } \\
\qquad\left(\mathrm{m}^{2} / \mathrm{g}\right)\end{array}$ & $\begin{array}{l}\text { Pore Diameter } \\
\qquad(\mathrm{nm})\end{array}$ & $\begin{array}{l}\text { Pore Volume } \\
\qquad\left(\mathrm{cm}^{3} / \mathrm{g}\right)\end{array}$ \\
\hline $\mathrm{RH}$ & 10.43 & 5.71 & 0.025 \\
\hline CBSC-1-3-5 & 42.81 & 4.85 & 0.062 \\
\hline CBSC-1-3-20 & 40.41 & 4.89 & 0.078 \\
\hline CBSC-2-4-20 & 47.69 & 6.46 & 0.103 \\
\hline Conv. CBSC & 37.01 & 6.44 & 0.018 \\
\hline $\begin{array}{l}\text { Glucose derived } \\
\text { catalyst* }\end{array}$ & 4.10 & 4.00 & 0.440 \\
\hline $\begin{array}{c}\text { Cellulose derived } \\
\text { catalyst* }\end{array}$ & 5.70 & 5.10 & 0.520 \\
\hline $\begin{array}{l}\text { Starch derived } \\
\text { catalyst* }\end{array}$ & 7.20 & 8.20 & 0.810 \\
\hline Amberlyst-15 ${ }^{[9]}$ & 45.00 & - & - \\
\hline
\end{tabular}

Figure 3 highlights the effect of different heating systems on the surface properties of the mesoporous carbon materials. The microwave and the conventional CBSC samples show a slightly different $\mathrm{N}_{2}$ adsorption-desorption isotherm but relatively similar pore size distribution. 
However, the conventional CBSC catalyst shows an isotherm of type IV with a larger hysteresis loop than the microwave CBSC catalyst, which has type II isotherm. Isotherms of type II are theoretically assigned to non-porous solids but in practice are often applicable equally to porous solids [50]. Hence, the microwave CBSC catalyst is considered porous as shown previously from SEM images. In addition, the distinction between isotherm II and IV is without practical significance in the low pressure range which is the case herein. At high relative vapour pressures, the adsorption-desorption isotherms of a given material is dependent on the restrictions of adsorption by the pore width. At low pressure range, materials such as microwave CBSC have such a great volume of relatively large pores $(2-50 \mathrm{~nm})$ that this restriction is negligible. Therefore, the isotherm of type II obtained at such low pressure is effectively not different from the conventional CBSC catalyst isotherm. The effect of the microwave preparation time is shown in the Supplement Information, Figure S2. The microwave catalyst is mesoporous, with pore sizes in the $2-50 \mathrm{~nm}$ range, while the conventional catalyst is similarly mesoporous but with a narrower range of pore sizes, $<20 \mathrm{~nm}$.

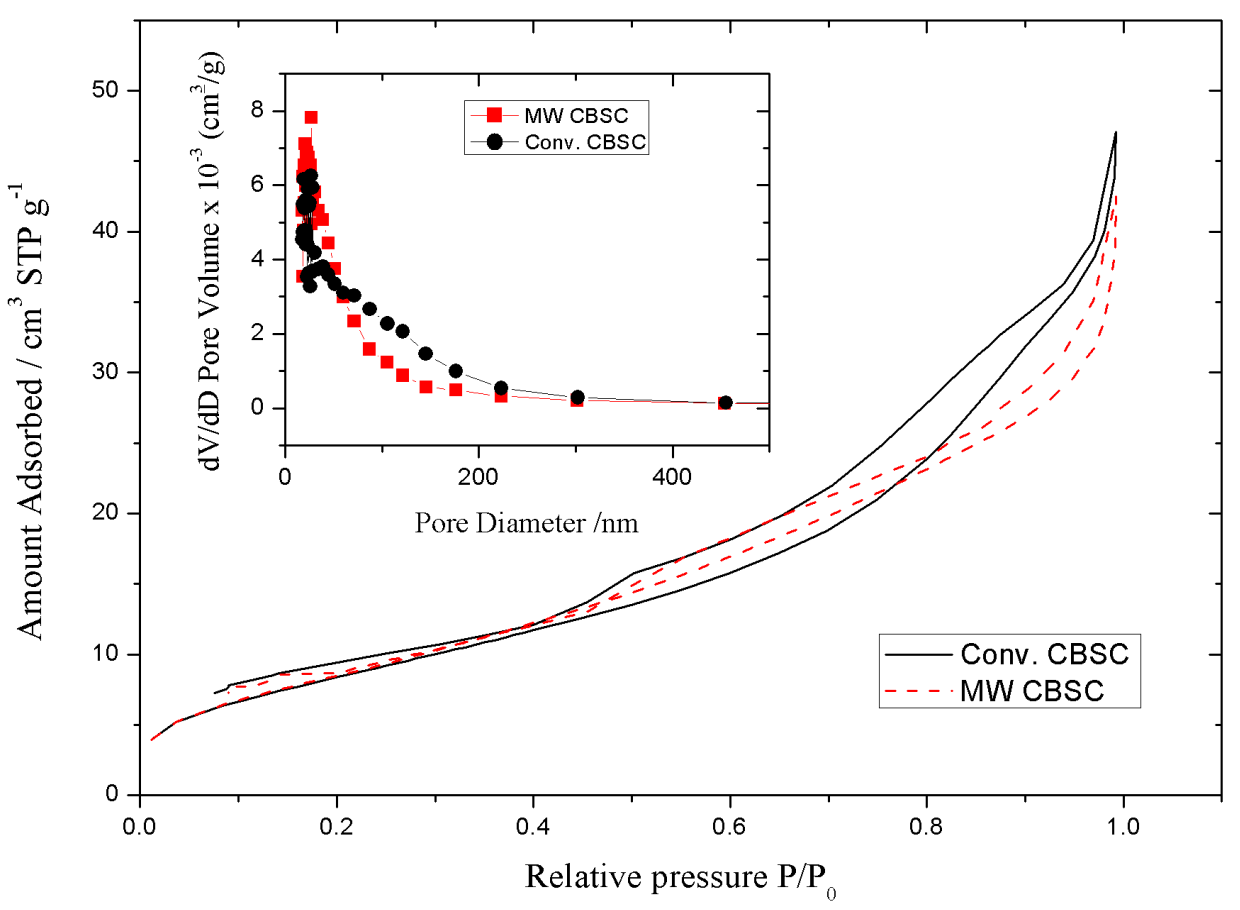


Figure $3 \mathrm{~N}_{2}$ adsorption-desorption isotherm and pore size distribution of conventional and microwave CBSC

\subsection{XRD analysis}

The XRD of the RH feedstock and CBSC are illustrated in Figure 4. No crystalline structures are observed. Instead strong broad peaks are observed at Bragg $2 \theta$ angle of $20^{\circ}$ and a weak peak at $35^{\circ}$ can be assigned to reflections from (002) and (100) planes of graphite, implying an amorphous structure of silica in the RH $[31,36]$. The broad nature of the peak was also attributed to hydrogen bond transformation in cellulose during the heat treatment and acid addition [49]. Furthermore, the low crystallinity is believed to be due to the large amount of amorphous cellulose in the catalysts [49]. The XRD analysis before and after the carbonisation and sulphonation shows a significant reduction of the intensity in the $\mathrm{RH}$ as compared to the CBSC samples between ca. $20^{\circ}$ to $30^{\circ}$. The decrease and the broadening of the CBSC XRD peak is attributed to the amorphous nature of carbon composed of aromatic carbon sheets oriented in a random manner [37]. 


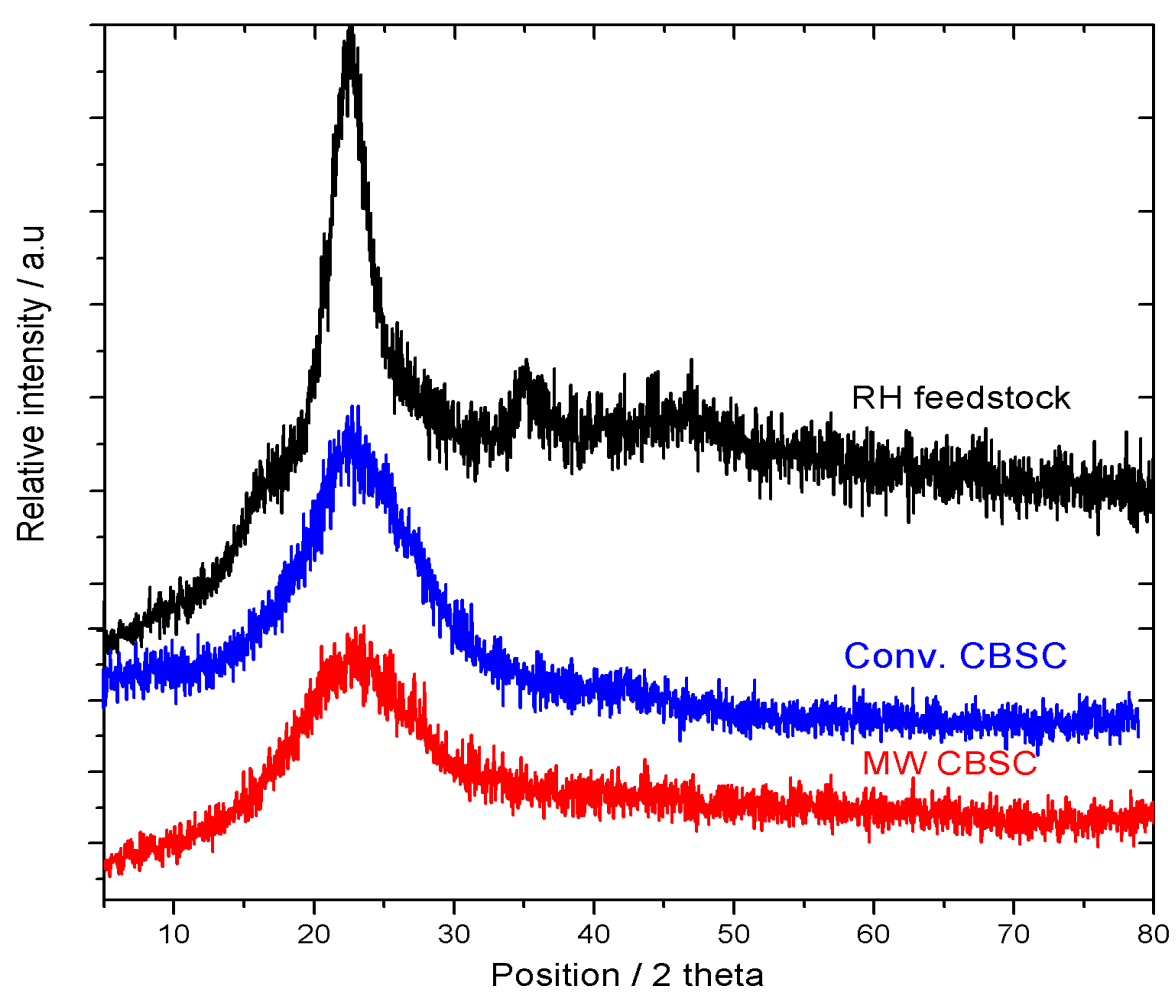

Figure 4 XRD of RH and CBSC-1-3-10 and CBSC-1-4-10

\section{Conclusion}

RH derived CBSC were prepared using conventional and MW heating systems. The results showed that MW prepared CBSC exhibited high acidity, high sulphur content and high porosity. This was achieved at significantly shorter reaction times (5-20 min vs $12 \mathrm{~h}$ ) and lower temperatures $\left(200{ }^{\circ} \mathrm{C}\right.$ vs $\left.400{ }^{\circ} \mathrm{C}\right)$ than the conventional carbonisation. The sulphur content of MW CBSC was much high than that of CBSC prepared by conventional heating $(4.91 \%$ and $1.11 \%$, respectively). The microwave prepared CBSC also showed higher total acid density. An average total acidity of $4.16 \mathrm{mmol} \mathrm{H}^{+} / \mathrm{g}$ was achieved as compared to the commercial analogue $(4.60 \mathrm{mmol} \mathrm{H} / \mathrm{g})$, which was itself better than for catalysts made by conventional heating $(1.76 \mathrm{mmol} \mathrm{H} / \mathrm{g})$. FTIR studies confirmed the successful attachment of sulphonic acid groups. The morphological study showed that microwave CBSC presented a highly porous 
structure, whilst conventional CBSC catalysts showed a dense biomass surface covered with some fragments. The current study presents a promising preparation method for making carbon based solid acid catalyst from biomass material in a time-saving and energy efficient manner. The catalysts' activity in transesterification reactions remains to be assessed. 


\section{Acknowledgement}

This material is based upon work supported by the Newton fund from the British Council (Ref:

172702808). We thank Mr Gary Robinson for his assistance with SEM measurements.

\section{References}

[1] N. Soltani, A. Bahrami, M.I. Pech-Canul, L.A. Gonzàlez, Review on the physicochemical treatments of rice husk for production of advanced materials, Chem. Eng. J. 264 (2015) 899-935.

[2] L. Canilha, V.T.O. Santos, G.J.M. Rocha, J.B. Almeida E Silva, M. Giulietti, S.S. Silva, M.G.A. Felipe, A. Ferraz, A.M.F. Milagres, W. Carvalho, A study on the pretreatment of a sugarcane bagasse sample with dilute sulfuric acid, J. Ind. Microbiol. Biotechnol. 38 (2011) 1467-1475.

[3] K.Y. Foo, B.H. Hameed, Coconut husk derived activated carbon via microwave induced activation: Effects of activation agents, preparation parameters and adsorption performance, Chem. Eng. J. 184 (2012) 57-65.

[4] L. Luduena, D. Fasce, V.A. Alvarez, P.M. Stefani, Nanocellulose from rice husk following alkaline treatment to remove silica, BioResources. 6 (2011) 1440-1453.

[5] P. Binod, R. Sindhu, R.R. Singhania, S. Vikram, L. Devi, S. Nagalakshmi, N. Kurien, R.K. Sukumaran, A. Pandey, Bioethanol production from rice straw: An overview, Bioresour. Technol. 101 (2010) 4767-4774.

[6] M.-J. Jeon, S.-S. Kim, J.-K. Jeon, S.H. Park, J.M. Kim, J.M. Sohn, S.-H. Lee, Y.-K. Park, Catalytic pyrolysis of waste rice husk over mesoporous materials, Nanoscale Res. Lett. 7 (2012) 18.

[7] P. Kaparaju, C. Felby, Characterization of lignin during oxidative and hydrothermal pre-treatment processes of wheat straw and corn stover, Bioresource. Technol. 101 (2010) 3175-3181.

[8] F. Adam, S. Balakrishnan, P.-L. Wong, Rice Husk Ash Silica As a Support Material for Ruthenium Based Heterogenous Catalyst, J. Phys. Sci. 17 (2006) 1-13.

[9] M. Ahiduzzaman, A. Islam, Preparation of Conducting Carbon From Rice Husk Char, J. Mech. Eng. M (2013) 10-11.

[10] H. Chen, H. Wang, L. Yang, Y. Xiao, High Specific Surface Area Rice Hull Based Porous Carbon Prepared for EDLCs, Int. J. Electrochem. 7 (2012) 4889-4897.

[11] S.B. Qadri, M.A. Imam, A.W. Fliflet, B.B. Rath, R. Goswami, J.D. Caldwell, Microwave-induced transformation of rice husks to SiC, J. Appl. Phys. 111 (2012) 15 . 
[12] L. Wang, X. Wang, B. Zou, X. Ma, Y. Qu, C. Rong, Y. Li, Y. Su, Z. Wang, Preparation of carbon black from rice husk by hydrolysis, carbonization and pyrolysis, Bioresour. Technol. 102 (2011) 8220-8224.

[13] P. Ling, X. He, N. Zhao, M. Yu, X. Zhang, M. Zheng, T. Zhu, Facile preparation of porous carbons from rice husk by microwave heating for supercapacitors, ICMREE 2013 - Proc. 2013 Int. Conf. Mater. Renew. Energy Environ. 2 (2013) 524-528.

[14] F. Ataya, M. a Dub, M. Ternan, M. a Dube, Acid-Catalyzed Transesterification of Canola Oil to Biodiesel under Single- and Two-Phase Reaction Conditions AcidCatalyzed Transesterification of Canola Oil to Biodiesel under Single- and Two-Phase Reaction Conditions, Energy. (2007) 2450-2459.

[15] J. Otera, Transesterification, Chem. Rev. 93 (1993) 1449-1470.

[16] M. Zhang, A. Sun, Y. Meng, L. Wang, H. Jiang, G. Li, Catalytic Performance of Biomass Carbon-Based Solid Acid Catalyst for Esterification of Free Fatty Acids in Waste Cooking Oil, Catal. Surv. from Asia. 19 (2015) 61-67.

[17] X. Fu, J. Chen, X. Song, Y. Zhang, Y. Zhu, J. Yang, C. Zhang, Biodiesel Production Using a Carbon Solid Acid Catalyst Derived from $\beta$-Cyclodextrin, J. Am. Oil Chem. Soc. 92 (2015) 495-502.

[18] S. Kang, J. Ye, J. Chang, Recent Advances in Carbon-Based Sulfonated Catalyst:IrPreparation and Application, Int. Rev. Chem. Eng. 5 (2013) 133-144.

[19] A. Zali, K. Ghani, A, Shokrolahi, MH, Keshavarz, Carbon-Based Solid Acid as an Efficient and Reusable Catalyst for Cross-Aldol Condensation of Ketones with Aromatic Aldehydes under Solvent-Free Conditions. Chinese Journal of Catalysis 29 (2008) 602-606.

[20] T. Liu, Z. Li, W. Li, C. Shi, Y. Wang, Preparation and characterization of biomass carbon-based solid acid catalyst for the esterification of oleic acid with methanol, Bioresour. Technol. 133 (2013) 618-621.

[21] S. Li, Z. Gu, B.E. Bjornson, A. Muthukumarappan, Biochar based solid acid catalyst hydrolyze biomass, J. Environ. Chem. Eng. 1 (2013) 1174-1181.

[22] M. Hara, T. Yoshida, A. Takagaki, T. Takata, J.N. Kondo, S. Hayashi, K. Domen, A carbon material as a strong protonic acid, Angew. Chemie - Int. Ed. 43 (2004) 29552958.

[23] A. Takagaki, M. Toda, M. Okamura, J.N. Kondo, S. Hayashi, K. Domen, M. Hara, Esterification of higher fatty acids by a novel strong solid acid, Catal. Today. 116 (2006) 157-161.

[24] M. Toda, A. Takagaki, M. Okamura, JN. Kondo, S. Hayashi, K. Domen, M. Hara: Green chemistry: Biodiesel made with sugar catalyst, Nature. 438 (2005) 178-178.

[25] Y. Wu, Z. Fu, D. Yin, Q. Xu, F. Liu, C. Lu, L. Mao, Microwave-assisted hydrolysis of crystalline cellulose catalyzed by biomass char sulfonic acids, Green Chem. 12 (2010) 696. 
[26] A.M. Dehkhoda, A.H. West, N. Ellis, Biochar based solid acid catalyst for biodiesel production, Appl. Catal. A Gen. 382 (2010) 197-204.

[27] D.J. Macquarrie, J.H. Clark, E. Fitzpatrick, The microwave pyrolysis of biomass, Biofuels, Bioprod. Biorefining. 6 (2012) 549-560.

[28] V.L. Budarin, Y. Zhao, M.J. Gronnow, P.S. Shuttleworth, S.W. Breeden, D.J. Macquarrie, J.H. Clark, Microwave-mediated pyrolysis of macro-algae, Green Chem. 13 (2011) 2330.

[29] W.H. Chen, S.C. Ye, H.K. Sheen, Hydrolysis characteristics of sugarcane bagasse pretreated by dilute acid solution in a microwave irradiation environment, Appl. Energy. 93 (2012) 237-244.

[30] Z. Zhu, D.J. Macquarrie, R. Simister, L.D. Gomez, S.J.M. Mason, Microwave assisted chemical pretreatment of Miscanthus under different temperature regimes, Sustain Chem Process. 3 (2015) 1-13.

[31] K.Y. Foo, B.H. Hameed, Utilization of rice husks as a feedstock for preparation of activated carbon by microwave induced $\mathrm{KOH}$ and $\mathrm{K} 2 \mathrm{CO} 3$ activation, Bioresour. Technol. 102 (2011) 9814-9817.

[32] J. Adrian, B. Janaun, Development of sulfonated carbon catalysts for integrated biodiesel production, (2012) 20.

[33] Z. Fu, H. Wan, Q. Cui, J. Xie, Y. Tang, G. Guan, Hydrolysis of carboxylic acid esters catalyzed by a carbon-based solid acid, React. Kinet. Mech. Catal. 104 (2011) 313321.

[34] M. Hara, Biomass conversion by a solid acid catalyst, Energy Environ. Sci. 3 (2010) 601.

[35] L. Peng, A. Philippaerts, X. Ke, J. Van Noyen, F. De Clippel, G. Van Tendeloo, P.A. Jacobs, B.F. Sels, Preparation of sulfonated ordered mesoporous carbon and its use for the esterification of fatty acids, Catal. Today. 150 (2010) 140-146.

[36] O. Mašek, V. Budarin, M. Gronnow, K. Crombie, P. Brownsort, E. Fitzpatrick, P. Hurst, Microwave and slow pyrolysis biochar - Comparison of physical and functional properties, J. Anal. Appl. Pyrolysis. 100 (2013) 41-48.

[37] A.F. Lee, J. a Bennett, J.C. Manayil, K. Wilson, Heterogeneous catalysis for sustainable biodiesel production via esterification and transesterification., Chem. Soc. Rev. 43 (2014) 7887-7916.

[38] X.Y. Liu, M. Huang, H.L. Ma, Z.Q. Zhang, J.M. Gao, Y.L. Zhu, X.J. Han, X.Y. Guo, Preparation of a carbon-based solid acid catalyst by sulfonating activated carbon in a chemical reduction process, Molecules. 15 (2010) 7188-7196.

[39] W.Y. Lou, M.H. Zong, Z.Q. Duan, Efficient production of biodiesel from high free fatty acid-containing waste oils using various carbohydrate-derived solid acid catalysts, Bioresour. Technol. 99 (2008) 8752-8758. 
[40] J. Janaun, N. Ellis, Role of silica template in the preparation of sulfonated mesoporous carbon catalysts, Appl. Catal. A Gen. 394 (2011) 25-31.

[41] B.H. Shanks, Conversion of Biorenewable Feedstocks: New Challenges in Heterogeneous Catalysis, Industrial and Engineering Chemistry Research, (2010) 10212-10217.

[42] W.H. Chen, Y.J. Tu, H.K. Sheen, Disruption of sugarcane bagasse lignocellulosic structure by means of dilute sulfuric acid pretreatment with microwave-assisted heating, Appl. Energy. 88 (2011) 2726-2734.

[43] Y.M. Sani, A.O. Raji, P.A. Alaba, A.R. Abdul Aziz, W.M.A. Wan Daud, Palm frond and spikelet as environmentally benign alternative solid acid catalysts for biodiesel production, BioResources. 10 (2015) 3393-3408.

[44] H. Li, J. Lu, J. Mo, Physiochemical lignocellulose modification by the formosan subterranean termite, BioResources. 7 (2012) 675-685.

[45] C. Li, B. Knierim, C. Manisseri, R. Arora, H. V. Scheller, M. Auer, K.P. Vogel, B.A. Simmons, S. Singh, Comparison of dilute acid and ionic liquid pretreatment of switchgrass: Biomass recalcitrance, delignification and enzymatic saccharification, Bioresour. Technol. 101 (2010) 4900-4906.

[46] J.X. Sun, X.F. Sun, R.C. Sun, P. Fowler, M.S. Baird, Inhomogeneities in the Chemical Structure of Sugarcane Bagasse Lignin, J. Agric. Food Chem. 51 (2003) 6719-6725.

[47] FN. Sadon Asi, KN. Ismail, Comparative Study of Single and Multi-layered Fixed Bed Columns for the Removal of Multi-metal Element using Rice Husk Adsorbents. Jounal of Applied Science. 14 (2014) 1234-1243.

[48] H. Mao, D. Zhou, Z. Hashisho, S. Wang, H. Chen, H. Wang, Preparation of pinewood- and wheat straw-based activated carbon via a microwave-assisted potassium hydroxide treatment and an analysis of the effects of the microwave activation conditions, BioResources. 10 (2015) 809-821.

[49] YM. Sani, Development of Solid Acid Catalysts for Biodiesel Production From High Free Fatty Acid Feedstock. University of Malaya, Faculty of Engineering; 2015.

[50] G. Fagerlund, Determination of specific surface by the BET method, Materials and Structures. 6 (1973) 239-245. 


\section{Appendix A:}

\section{Supplement Information}

\section{Rice husk (RH)}

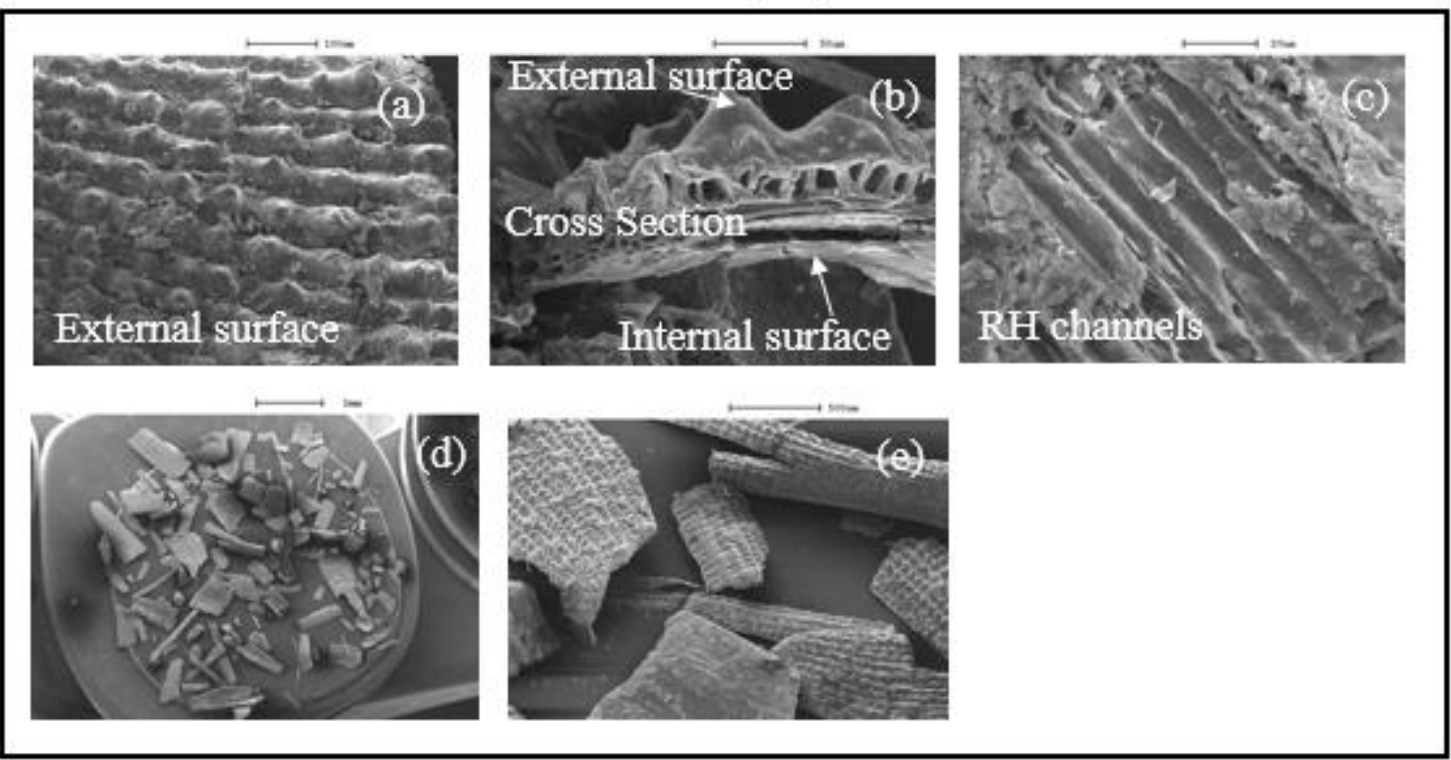

\section{Microwave CBSC}

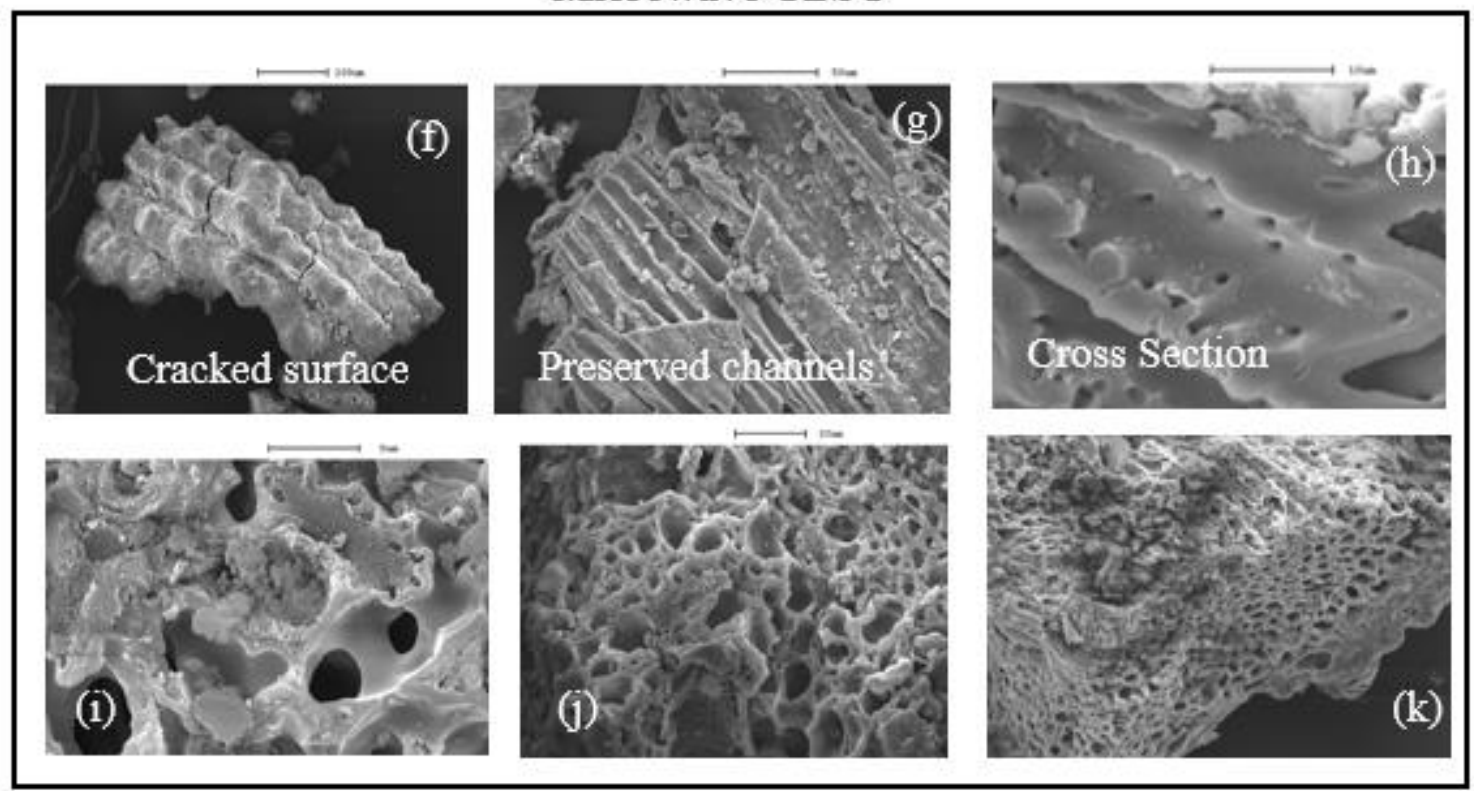

\section{Conventional CBSC}

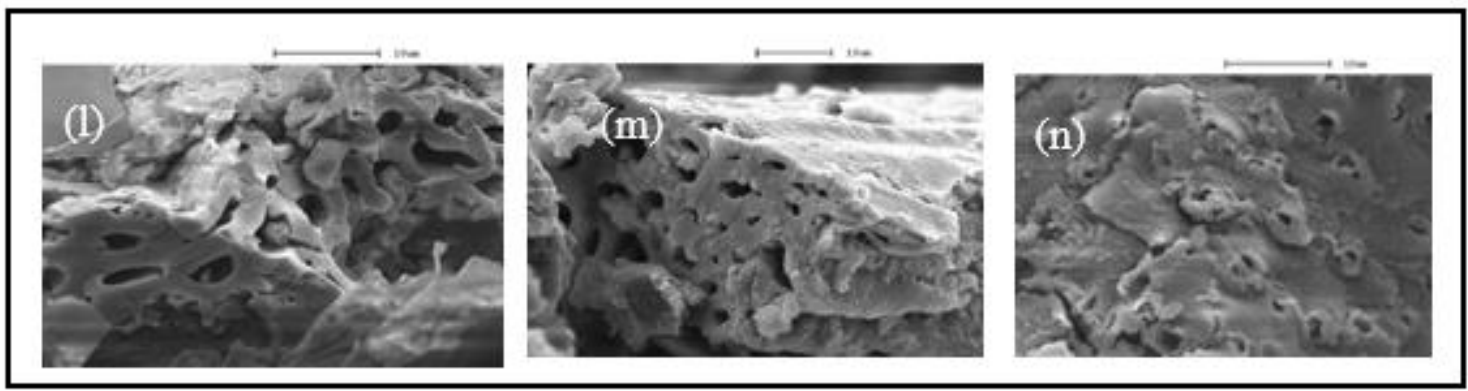


Figure S1 SEM images of RH feedstock, MW and Conv. CSBC samples

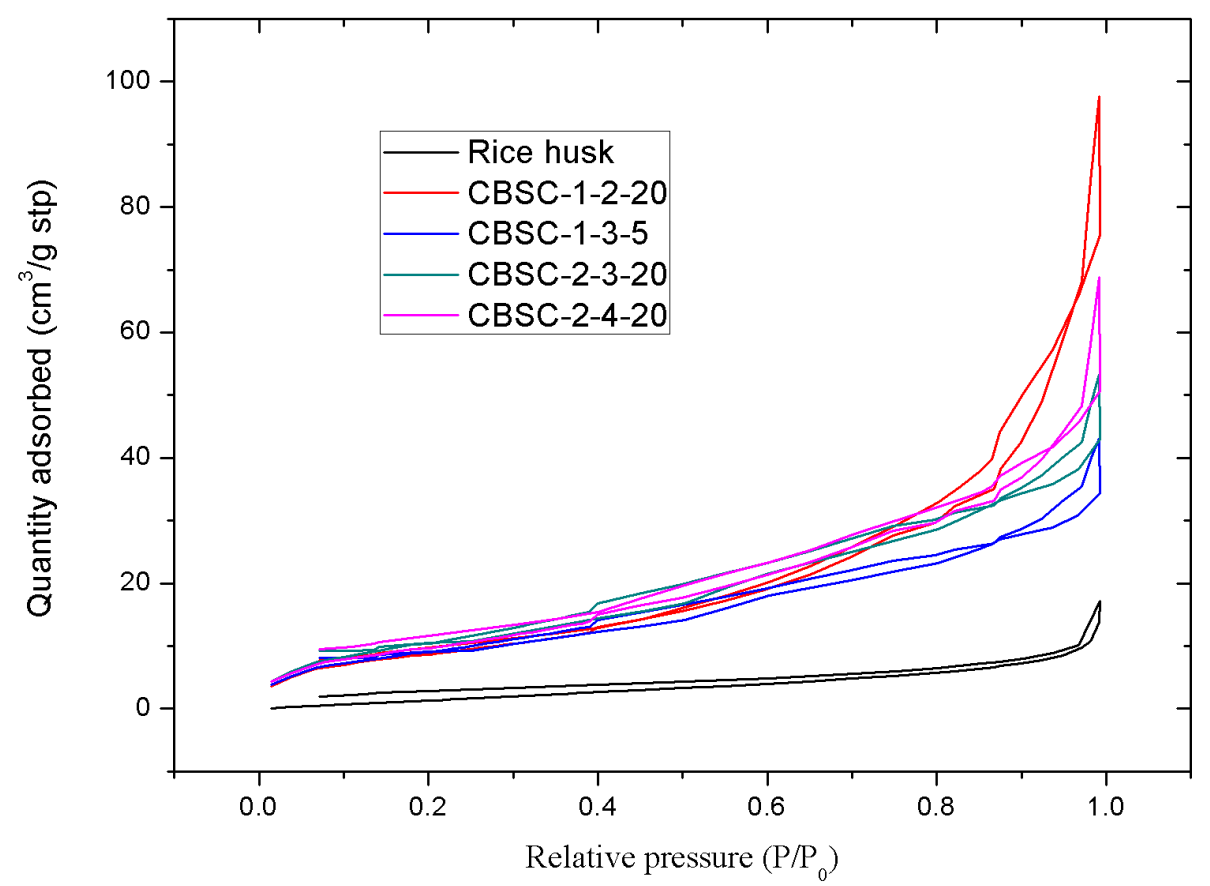

Figure $\mathrm{S} 2 \mathrm{~N}_{2}$ adsorption-desorption isotherm and pore size distribution of microwave CBSC

Table S1. Reaction conditions for MW CBSC

\begin{tabular}{|c|c|c|c|c|c|c|c|}
\hline \multirow[t]{2}{*}{ Sample name } & \multirow{2}{*}{$\begin{array}{c}\text { Carbonisation } \\
\text { conditions }\left(200^{\circ} \mathrm{C},\right. \\
30 \mathrm{~min}) \\
\text { Ratio of Rice Husk } \\
\text { to } \mathrm{H}_{2} \mathrm{SO}_{4}\end{array}$} & \multirow{2}{*}{$\begin{array}{c}\text { Char } \\
\text { yield }(g)\end{array}$} & \multirow{2}{*}{$\begin{array}{l}\text { Sulphonation } \\
\text { time (min) }\end{array}$} & \multicolumn{4}{|c|}{$\begin{array}{c}\text { Elemental component } \\
\text { (wt.\%) }\end{array}$} \\
\hline & & & & $\mathrm{C}$ & $\mathrm{H}$ & $\mathrm{N}$ & $S$ \\
\hline CBSC-1-3-5 & \multirow[t]{3}{*}{ 1: 0.294} & 2.12 & 5 & 39.21 & 2.68 & 0.40 & 4.22 \\
\hline CBSC-1-3-10 & & 1.98 & 10 & 38.32 & 2.71 & 0.40 & 3.06 \\
\hline CBSC-1-3-20 & & 2.05 & 20 & 38.71 & 2.27 & 0.46 & 4.91 \\
\hline CBSC-1-4-5 & \multirow[t]{3}{*}{$1: 0.392$} & 2.12 & 5 & 37.44 & 2.19 & 0.38 & 2.52 \\
\hline CBSC-1-4-10 & & 2.12 & 10 & 32.69 & 1.98 & 0.38 & 2.54 \\
\hline CBSC-1-4-20 & & 2.01 & 20 & 33.92 & 2.28 & 0.46 & 4.12 \\
\hline CBSC-2-3-5 & \multirow[t]{3}{*}{ 1: 0.588} & 2.04 & 5 & 38.08 & 2.41 & 0.37 & 3.63 \\
\hline CBSC-2-3-10 & & 2.09 & 10 & 33.60 & 2.14 & 0.34 & 2.69 \\
\hline CBSC-2-3-20 & & 2.11 & 20 & 37.90 & 2.48 & 0.32 & 3.74 \\
\hline CBSC-2-4-5 & \multirow[t]{3}{*}{ 1: 0.784} & 2.12 & 5 & 36.44 & 2.10 & 0.40 & 2.56 \\
\hline CBSC-2-4-10 & & 2.33 & 10 & 36.18 & 1.85 & 0.41 & 3.20 \\
\hline CBSC-2-4-20 & & 2.08 & 20 & 33.63 & 2.30 & 0.28 & 3.85 \\
\hline
\end{tabular}


